\title{
Using Textbook Readings, YouTube Videos, and Case Studies for Flipped Classroom Instruction of Engineering Design
}

\author{
Craig G. Merrett \\ Carleton University \\ Craig_Merrett@carleton.ca
}

\begin{abstract}
Flipped classroom instruction places the transfer of information outside of the class and focuses on the application of the information in the class. Applying flipped classroom instruction to engineering design courses is challenging because design is open-ended.

Three approaches were tested for second year and fourth year students taught by the same instructor in six course offerings. All course offerings used case studies. Three offerings were taught using traditional methods such as blackboard notes or PowerPoint presentations. The other course offerings used flipped classroom instruction that applied assigned textbook readings or assigned, instructor-created YouTube videos.

A statistical assessment of the final exam scores show that flipped classroom instruction using assigned textbook readings result has a negative impact on final exam performance. YouTube videos and case studies have positive impacts on final exam performance.
\end{abstract}

Keywords: YouTube, flipped classroom instruction, textbook use, case study based learning, podcast

\section{INTRODUCTION}

In traditional lecture formats, the instructor transfers information to the students via blackboard notes or PowerPoint slides. Outside the class hours, the students are expected to apply the knowledge through assignments and projects. In flipped classroom instruction (FCI), information is transmitted outside the lecture time via videos and textbook readings. Teaching engineering design by FCI is challenging because of the open-ended nature of design. Also, engineering design should cultivate the students' problem solving creativity, which is an ambiguous skill. The objective of this study is to determine the effects of variations of FCI and case studies on design courses. Two FCI approaches were attempted, one using a mandatory textbook for instruction outside the classroom, while the second used YouTube videos created by the author.

\section{LITERATURE REVIEW}

Flipped classroom instruction originated in the United States as a result of experiments with hybrid learning, active learning, and problem based learning [1, 2]. At the university level, a number of institutions have experimented with flipped instruction with intriguing results. The Department of Mathematics at the University of Michigan in Ann Arbor found that students in a flipped classroom setting made larger gains in understanding compared to a traditional lecture setting [2]. The use of FCI does have an impact on teaching evaluation scores. Courses at Harvard University taught by flipped instruction had an average score that was half that of a course taught by traditional lecture methods [2].

Engineering students' use of textbooks has been investigated by several researchers. In a study of 10 , fourth year material engineering students at a large American university, researchers found that the students used the textbook for reference information, finding equations, and locating examples that they could work backward and apply to a new problem. The conclusion of the study was that students use textbooks in a limited fashion that does not include conceptual understanding of the content [3].

The amount of time that students spend on various learning activities outside of the classroom has also been studied including their interaction time with course resources [4]. Students at the University of Wyoming and Texas Tech University enrolled in thermodynamics courses were asked to log their time for various activities. The results show that time spent reading the textbook was significantly lower than the time spent solving textbook problems. Students on average spent 37 minutes per week reading the textbook. The same study correlated the time spent on the activities with various grades including the final exam grade. Textbook use was weakly correlated to final exam success [4].

The same researchers conducted a later study, across all undergraduate year levels and engineering degree programs at the two institutions, that confirmed that students average between 28 minutes and 38 minutes per week for textbook reading. The researchers also found 
that less than $15 \%$ of students read textbooks for the purposes of learning beyond the lecture content [5].

The FCI using YouTube videos fits within the use of electronic resources for instruction such as podcasting. Students find podcasts at least as useful as traditional supplemental materials such as written handouts, and the majority of students will download or view podcasts. The primary use of these materials by students is for reviewing or preparing for assessments [6]. Students have found podcasts to be more useful for reviewing than textbooks and their notes [7]. Students view podcasts positively and the podcasts may increase their interest in a course material. Further, students have demonstrated an interest in producing podcasts [8].

Case studies have been incorporated into a number of engineering courses and appear as part of problem based learning. Case studies are effective at improving students' higher order cognitive skills [9, 10]. Case studies test students' abilities to solve open-ended problems that integrate multiple concepts. A small study of women in engineering using a multimedia case study of a power plant found that women perceived more opportunities to learn from the case study than men. The result was higher scores on a perceived cognitive skill development test [11].

\section{COURSES CONSIDERED}

Four courses taught in the Department of Mechanical and Aerospace Engineering at Carleton University by the author are included in this study. The courses are MECH 4104: Vibration Analysis, MECH 4003: Mechanical Systems Design, MAAE 2700: Engineering Materials, and SREE 4001: Efficient Energy Conversion

MECH 4104 is a fourth year technical elective course that provides analysis and design skills for vibrating systems. The course is predominantly taken by students in the mechanical engineering program. MECH 4003 is a mandatory course for students in the mechanical engineering program, and includes a variety of mechanical systems such as gear trains, hydraulics, and design optimization. SREE 4001 is a mandatory course for students in the sustainable and renewable energy engineering program, a specialized program that developed from the mechanical engineering program. SREE 4001 includes power plant design such as hydroelectric turbines, steam turbines, boilers, and cooling towers. MAAE 2700 is a second year, mandatory course for students in all degree programs offered by the Department. The course is the first introduction to materials science and material selection for design.

The author taught MECH 4104 and MAAE 2700 twice, and MECH 4003 and SREE 4001 once. The six course offerings form the data set examined within this study. Further, the study is constrained to the final exam scores because the final exam was worth more than $50 \%$ of the final grade in each course and was the sole assessment evaluated by the author directly. The courses include other assessments evaluated by teaching assistants. These assessments are excluded to reduce the number of variables within the study. The final exam scores were anonymized by Carleton University's Educational Development Centre.

The terms, class size, and variations in the delivery of the courses are recorded in Table 1 . Under instruction method an entry of "Traditional" means a lecture format with notes on the blackboard or by PowerPoint. Flipped instruction required that the students either read assigned textbook sections or watch author-created YouTube videos prior to a given lecture.

Table 1: Course Data and Methods of Instruction

\begin{tabular}{|c|c|c|c|}
\hline Course & Term & $\begin{array}{c}\text { Number of } \\
\text { Students }\end{array}$ & $\begin{array}{c}\text { Instruction } \\
\text { Method }\end{array}$ \\
\hline \multirow{3}{*}{ MECH 4104 } & $\begin{array}{c}\text { Winter } \\
2012\end{array}$ & 21 & Traditional \\
\cline { 2 - 4 } & $\begin{array}{c}\text { Winter } \\
2013\end{array}$ & 19 & $\begin{array}{c}\text { Flipped } \\
\text { with } \\
\text { YouTube }\end{array}$ \\
\hline \multirow{3}{*}{ MECH 4003 } & $\begin{array}{c}\text { Fall } \\
2013\end{array}$ & 69 & $\begin{array}{c}\text { Flipped } \\
\text { with } \\
\text { textbook }\end{array}$ \\
\hline \multirow{2}{*}{ SREE 4001 } & $\begin{array}{c}\text { Fall } \\
2014\end{array}$ & 28 & $\begin{array}{c}\text { Traditional } \\
\text { MAAE 2700 }\end{array}$ \\
\cline { 2 - 5 } & Winter & 88 & $\begin{array}{c}\text { Traditional } \\
\text { Winter }\end{array}$ \\
\hline \multirow{2}{*}{2014} & 102 & $\begin{array}{c}\text { Flipped } \\
\text { with } \\
\text { textbook }\end{array}$ \\
\hline
\end{tabular}

The inclusion of the traditional lecture formats are to provide a baseline to assess the effects of FCI with a textbook, FCI with YouTube videos, and the use of case studies.

The effects of the different instruction methods are assessed using statistical measures of the distributions of the final exam scores. The distributions are compared against the distribution for the relevant traditional instruction of the equivalent course. The comparison is completed using the Welch two sample t-test after confirmation of normality of the distributions by the Shapiro-Wilk normality test. For comparisons involving non-normal distributions, the Kolgomorov-Smirnov test and the Kruskal-Wallis test are used.

\section{RESULTS FOR FLIPPED CLASSROOM INSTRUCTION WITH A TEXTBOOK}

Two pairs of courses are considered for the FCI with a textbook. The first pair is the two offerings of MAAE 
2700. The second pair is MECH 4003 compared to SREE 4001. These two courses are compared because they are both mandatory courses for fourth year engineering students in mechanical engineering or mechanical engineering derived programs. Thus the students have similar academic backgrounds and course loads. Both courses included a large term project and secondary assessments thus their work loads are comparable.

\subsection{MAAE 2700 Textbook Results}

MAAE 2700: Engineering Materials is taught to second year students in the aerospace, mechanical, sustainable and renewable energy, and biomedicalmechanical engineering disciplines. During the Winter 2013 term, the author delivered this course using PowerPoint slides in the classroom meeting time. The slides conveyed the bulk of the course content with a mandatory textbook to supplement the content and to provide homework problems [12]. The slides were developed from the textbook by previous instructors and closely matched the textbook content. Qualitative observations by the author were that class attendance declined throughout the term and students rarely used the textbook.

During the Winter 2014 term, the author flipped the classroom in an attempt to improve class attendance based on earlier success with flipped teaching in MECH 4104. The students were required to read specific sections of the textbook prior to each lecture according to a detailed schedule provided by author. The students also answered one to three conceptual questions through the online course management site. The author reviewed the responses prior to class and tailored the lecture content to focus on the most common errors. The lectures were focused on examples and applying the textbook content. The final exams for both offerings of MAAE 2700 were identical in format and used similar questions.

The distributions of the final exam grades from each offering are shown in Figure 1 as overlaid histograms. The means of the distributions and the p-values from the Shapiro-Wilk tests are shown in Table 2.

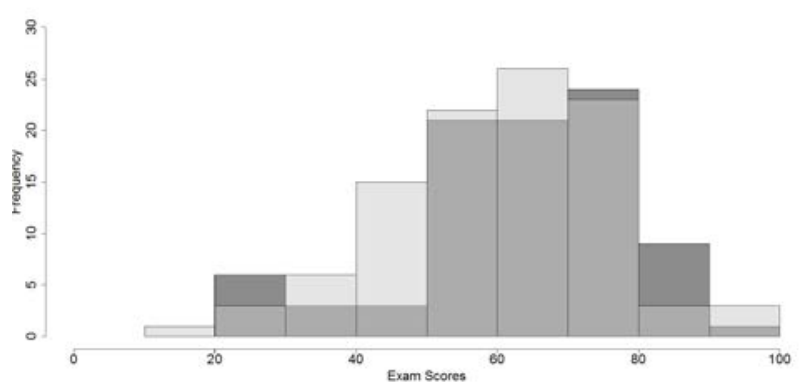

Fig. 1. MAAE 2700 final exam score distribution, dark grey - Winter 2013, light grey - Winter 2014
Table 2: MAAE 2700 Mean Scores

\begin{tabular}{|c|c|c|}
\hline Term & Mean Exam Score & $\begin{array}{c}\text { Shapiro-Wilk } \\
\text { p-value }\end{array}$ \\
\hline Winter 2013 & 64 & $4.79 \times 10^{-5}$ \\
\hline Winter 2014 & 60 & 0.325 \\
\hline
\end{tabular}

The Shapiro-Wilk normality test returns that the Winter 2013 exam score distribution is non-normal while the Winter 2014 exam score distribution is normal. Thus, to compare these two distributions requires the use of the Kolgomorov-Smirnov two-sample test and the KruskalWallis test as they are suitable for non-normal distributions.

The Kolgomorov-Smirnov test for the two offerings of MAAE 2700 returns $\mathrm{D}=0.194$ and the critical value for this sample size is 0.198 . The Kruskal-Wallis test returns the statistic $H$ which is compared to a $\chi^{2}$ distribution with 1 degree of freedom. For this comparison, $\mathrm{H}=4.98$ which corresponds to a level of significance between 0.025 and 0.05 .

The implication of these results is that the FCI with a textbook has a negative effect on MAAE 2700 exam performance. The effect is expected because students' use of textbooks does not include conceptual understanding of the content [3].

\subsection{MECH 4003 and SREE 4001 Textbook Results}

MECH 4003: Mechanical Systems Design and SREE 4001: Efficient Energy Conversion are taught to fourth year students in the mechanical engineering, and in the sustainable and renewable energy engineering programs respectively. The author taught MECH 4003 during the Fall 2013 term and SREE 4001 during the Fall 2014 term.

MECH 4003 was delivered via FCI using assigned textbook readings [13]. The textbook is mandatory and has been used for many years within the course and a prerequisite course. The students were required to complete conceptual problems through the online management site prior to each lecture. The author reviewed the answers and tailored the lecture material to address any common errors. The remainder of the lecture periods involved example problems solved on the blackboard, and case studies. The case studies originated from the Transportation Safety Board of Canada and the students were typically given a summary of the accident and any relevant data. Working in groups of four, the students had to apply the lecture content to determine the cause(s) of the accident.

SREE 4001 was delivered by traditional lecture using notes written on the blackboard. The notes were developed by the author from a number of resources. During the associated problem analysis sessions, the 
students solved case studies in groups of four. The case studies were developed by the author from existing literature on power plant design. The studies required that the students apply the lecture content to determine the performance of power plant components.

The two courses are compared to provide further data regarding the FCI using a textbook. SREE 4001 is the baseline because the course used traditional instruction but retained the case study use that appeared in $\mathrm{MECH}$ 4003. Further, both courses used case study derived final exams thus their evaluations are similar.

The distributions of the final exam grades from each course are shown in Figure 2 with overlaid histograms. The means of the distributions and the Shapiro-Wilk pvalues are shown in Table 3.

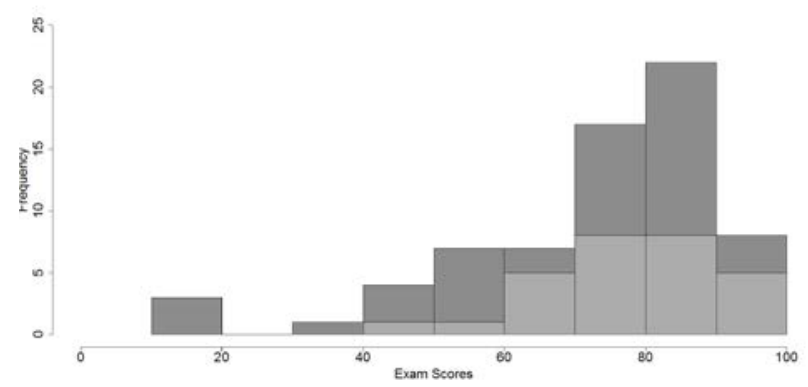

Fig. 2. MECH 4003 and SREE 4001 final exam score dark grey - MECH 4003, light grey - SREE 4001

Table 3: MECH 4003 and SREE 4001 Mean Scores

\begin{tabular}{|c|c|c|}
\hline Course & Mean Exam Score & $\begin{array}{c}\text { Shapiro-Wilk } \\
\text { p-value }\end{array}$ \\
\hline MECH 4003 & 73 & $1.511 \times 10^{-5}$ \\
\hline SREE 4001 & 78 & 0.092 \\
\hline
\end{tabular}

The MECH 4003 exam score distribution is nonnormal, while the SREE 4001 distribution is normal. The Kolmogorov-Smirnov test returns $\mathrm{D}=0.19$, and the critical value is 0.304 for this sample size. The KruskalWallis test returns $\mathrm{H}=1.33$ which is above typical levels of significance. The two tests indicate that there is no significant difference between the students' performance on the final exams of MECH 4003 and SREE 4001.

The implication is that FCI with a textbook has no benefit in terms of final exam performance. The result is consistent with the earlier finding for MAAE 2700.

\section{RESULTS FOR FLIPPED CLASSROOM INSTRUCTION WITH YOUTUBE VIDEOS}

MECH 4104: Vibration Analysis is a technical elective taught to fourth year mechanical engineering students. The author delivered this course during the Winter 2012 and Winter 2013 terms. The Winter 2012 offering used a traditional lecture format with notes written on the blackboard. The Winter 2013 used the same notes; however, the author recorded himself writing the notes on a pad of paper and uploaded these videos to YouTube. Students were required to watch sets of videos prior to each lecture. During the lecture time, students were given exercises, experiments, and case studies to analyze. The final exams for both offerings were case study based and of similar formats.

The distributions of the final exam grades from each offering are shown in Figure 3 as overlaid histograms. The means of the distributions and the Shapiro-Wilk pvalues are shown in Table 4.

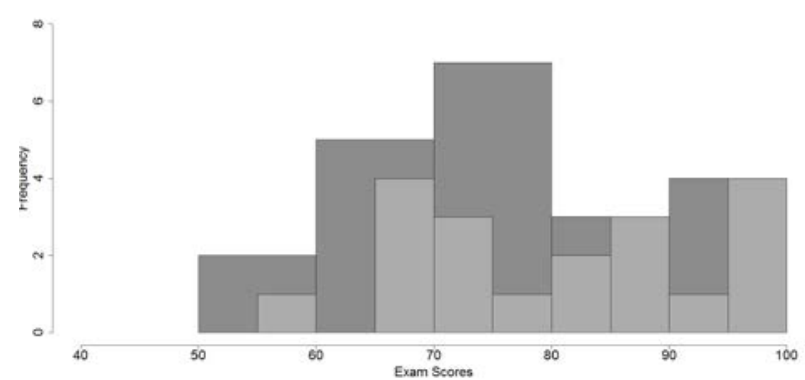

Fig. 3. MECH 4104 final exam score distribution, dark grey - Winter 2012, light grey - Winter 2013

Table 4: $\mathrm{MECH} 4104$ Mean Scores

\begin{tabular}{|c|c|c|}
\hline Term & Mean Exam Score & $\begin{array}{c}\text { Shapiro-Wilk } \\
\text { p-value }\end{array}$ \\
\hline Winter 2012 & 77 & 0.528 \\
\hline Winter 2013 & 81 & 0.153 \\
\hline
\end{tabular}

The distributions of the final exam scores from both offerings of MECH 4104 return Shapiro-Wilk p-values greater than 0.05, thus both are normal distributions and the Welch t-test may be used. A one-sided alternative is used because the mean exam scores suggest that the FCI with YouTube videos may have a positive benefit.

The Welch t-test returns a p-value of 0.156 indicating that there is approximately an $85 \%$ confidence that the higher average is statistically significant. The implication is that flipped instruction with YouTube videos has a positive benefit in terms of final exam performance. This result is consistent with the published findings for podcasts [7].

A second result from the FCI with YouTube videos is the number of minutes and views for the Winter 2013 term. The number of minutes spent viewing the YouTube videos per week is shown in Figure 4. 


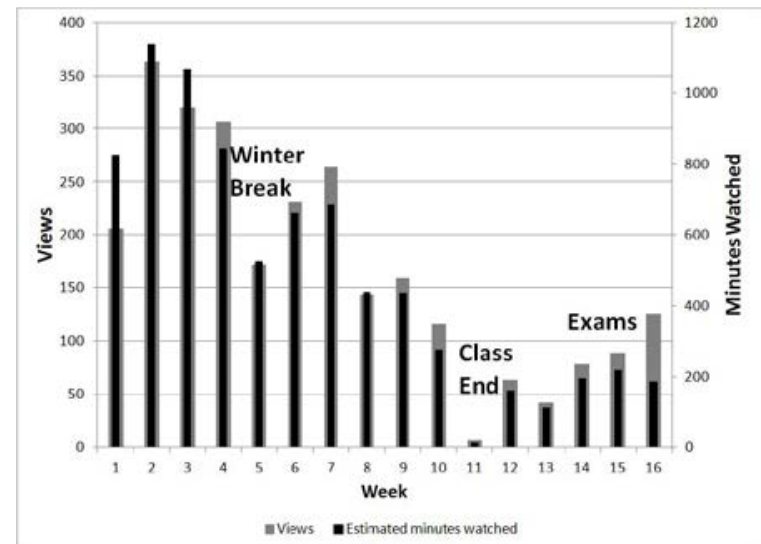

Fig. 4. MECH 4104 Winter 2013 - YouTube viewership

The number of views was higher for the first four weeks before a decrease during the Winter Break. The viewership increased after the break followed by a decline starting in Week 8. The decline is expected because the later portion of the course had fewer videos to watch. During the exam session, students reviewed the videos as shown by the views for Weeks 12 to 16 in Figure 4 .

Given that the course had 19 students, the estimated viewing time for the first seven weeks is 43 minutes per week. This viewing time is higher than the reported textbook usage of 28 to 38 minutes per week [5].

\section{RESULTS FOR CASE STUDY BASED LEARNING}

To determine the effects of case study based learning, the MECH 4104 Winter 2012 offering and SREE 4001 are compared. Both offerings used traditional lecture formats; however, SREE 4001 used case studies. The distributions of the final exam grades are shown in Figure 5 as overlaid histograms. The means of the distributions and the Shapiro-Wilk p-values are shown in Table 5.

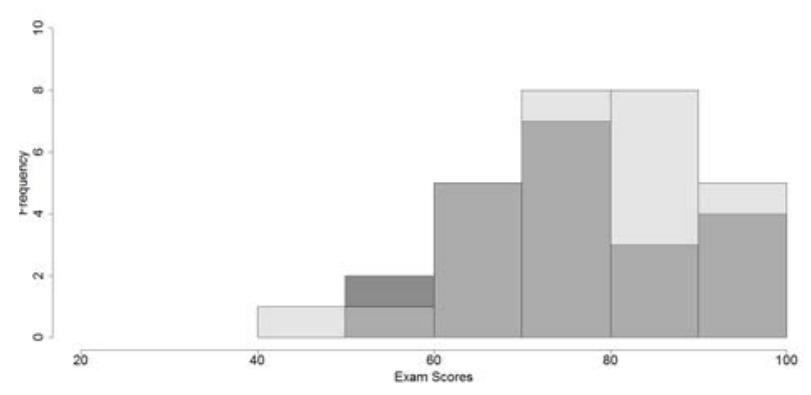

Fig. 5. Final exam score distribution for fourth year courses, dark grey - MECH 4104 Winter 2012, light grey SREE 4001 Fall 2014
Table 4: Fourth Year Courses Mean Scores

\begin{tabular}{|c|c|c|}
\hline Term & Mean Exam Score & $\begin{array}{c}\text { Shapiro-Wilk } \\
\text { p-value }\end{array}$ \\
\hline $\begin{array}{c}\text { MECH 4104 } \\
\text { Winter 2012 }\end{array}$ & 77 & 0.528 \\
\hline $\begin{array}{c}\text { SREE 4001 } \\
\text { Fall 2014 }\end{array}$ & 79 & 0.092 \\
\hline
\end{tabular}

The distributions are both normal; therefore, the onesided Welch t-test is used because the mean scores suggest that the use of case studies may be beneficial. The t-test returns a p-value of 0.33 indicating that there is approximately a $65 \%$ confidence that the higher mean exam score is statistically significant. The implication is that case study based learning has a positive benefit for final exam performance.

\section{TEACHING EVALUATION EFFECTS}

Researchers at Harvard University found that FCI had a negative impact on teaching evaluation scores [2]. The distributions of overall teaching evaluation scores for the courses taught by the author are shown in Figure 6 .

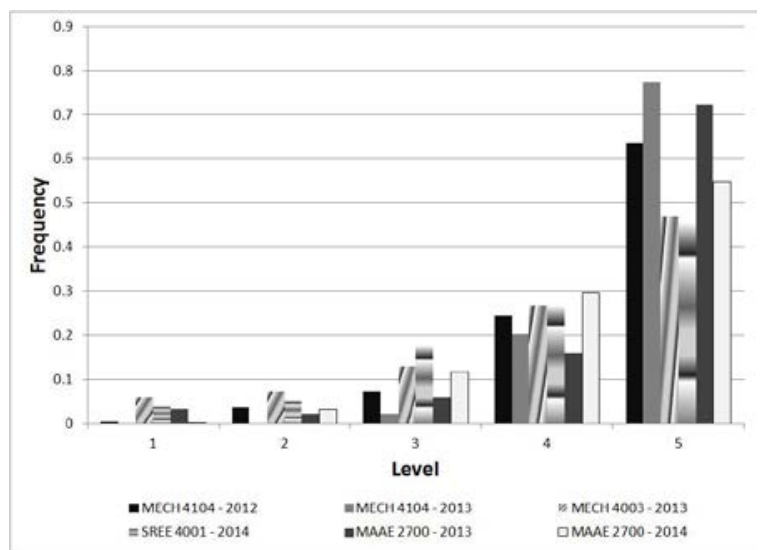

Fig. 6. Overall teaching evaluations - 1 is poor, 5 is excellent

The MECH 4104 scores show that the FCI, the 2013 offering, has a higher frequency of $5 \mathrm{~s}$ compared to the 2012 offering. Further that poor scores such as 1s and 2s are nonexistent; however, this course was a technical elective thus students who did not like the teaching method may have withdrawn.

The MECH 4003 and SREE 4001 scores show that the FCI using a textbook does increase the number of poor scores while having a minimal effect on the excellent scores. The textbook effect on poor scores is further seen with the MAAE 2700 scores because the 2014 offering used flipped instruction with a textbook. The textbook effect on excellent scores for MAAE 2700 is also negative, unlike MECH 4003 and SREE 4001. MAAE 2700 is a second year course thus the students have less 
developed study habits and require greater guidance from the instructor. Requiring the textbook to be read may be interpreted as a lack of guidance leading to a negative evaluation by the students.

\section{IMPROVEMENTS TO THE STUDY}

The study is limited by the sample sizes and number of course offerings. The YouTube instruction method was applied in only a single, technical elective for fourth year students. Fourth year students tend to be more motivated and more mature than the second year students. A larger study should be undertaken where YouTube instructional videos are implemented for mandatory courses at multiple year levels.

\section{CONCLUSIONS}

The final exams from four courses in the Department of Mechanical and Aerospace Engineering at Carleton University were studied to evaluate the effects of flipped classroom instruction using assigned textbook sections, instructor created YouTube videos, and case studies. The courses included two fourth year, mandatory, systems design courses, an elective fourth year vibrations course, and a mandatory second year materials engineering course.

The use of assigned textbook readings is found to have a negative impact on the final exam performance and on teaching evaluation scores. This result is consistent with published results that indicate that students use textbooks superficially. The use of YouTube videos and case studies was found to have a positive impact on final exam performance and on teaching evaluation scores which is consistent with reported results for podcasts and problem based learning.

\section{References}

[1] Sara Arnold-Garza, “The flipped classroom teaching model and its use for information literacy instruction,"

Communications in Information Literacy, vol. 8, no. 1, pp.722, 2014.

[2] Dan Berrett, "How 'flipping' the classroom can improve the traditional lecture," Chronicle of Higher Education, vol. 58, no. 25, A16, 2012. Available as of February 19, 2012 from http://chronicle.com/article/How-Flipping-theClassroom/130857/

[3] Christine S. Lee, Nathan J. McNeill, Elliot P. Douglas, Mirka E. Koro-Ljungberg, and David J. Therriault, "Indispensable resource? A phenomenological study of textbook use in engineering problem solving," Journal of Engineering Education, vol. 102, no. 2, pp. 269-288, 2013.
[4] Roman Taraban, Matthew W. Hayes, Edward E. Anderson, and M.P. Sharma, "Giving students time for the academic resources that work," Journal of Engineering Education, vol 93, no. 3, pp. 205-210, 2004.

[5] Roman Taraban, "Information fluency growth through engineering curricula: analysis of students' text-processing skills and beliefs,” Journal of Engineering Education, vol. 100, no. 2, pp. 397-416, 2011.

[6] Jonathan Copley, “Audio and video podcasts of lectures for campus-based students: production and evaluation of student use," Innovations in Education and Teaching International, vol. 44, no. 4, pp. 387-399, 2007.

[7] Chris Evans, "The effectiveness of m-learning in the form of podcast revision lectures in higher education," Computers \& Education, vol. 50, pp.491-498, 2008.

[8] Raymond Y.K. Lau, Rachel K.F. Ip, M.T. Chan, Ron ChiWai Kwok, Sharon W.M. Wong, and Johnny C.F.So, "Podcasting: an Internet-based social technology for blended learning," IEEE Internet Computing, vol. 14, no. 3, pp. 3341, 2010.

[9] Chetan S. Sankar, Virajanand Varma, and P.K. Raju, "Use of case studies in engineering education: assessment of changes in cognitive skills," Journal of Professional Issues in Engineering Education and Practice, vol. 134, pp. 287296, 2008.

[10] Randy V. Bradley, Chetan S. Sankar, Howard R. Clayton, Victor W. Mbarika, and P.K. Raju, "A study on the impact of GPA on perceived improvement of higher-order cognitive skills,” Decisions Sciences Journal of Innovative Education, vol. 5, no. 1, pp. 151-168, 2007.

[11] Victor W. Mbarika, Chetan S. Sankar, and P.K. Raju, "Identification of factors that lead to perceived learning improvements for female students," IEEE Transactions on Education, vol. 46, no. 1, pp. 26-36, 2003.

[12] William D. Callister, Jr. and David G. Rethwisch, Materials Science and Engineering: An Introduction, New York, NY: John Wiley \& Sons, 2014 ( $9^{\text {th }}$ ed. $), 960$ pp. \{ISBN: 978-1-118-32457-8\}

[13] Robert C. Juvinall and Kurt M. Marshek, Fundamentals of Machine Component Design, New York, NY: John Wiley \& Sons, 2012 ( th $^{\text {ed }}$ ed), 899 pp. \{ISBN: 978-1-118-01289-5\} 